\title{
US grapples with solutions to preventable medical errors
}

A

fter years of warnings from former United States president George Bush that frivolous medical malpractice lawsuits were driving doctors out of practice and inflating the cost of US health care, the weight of evidence now points to preventable errors - not misguided lawsuits - as the real source of the concerns.

In 6 consecutive State of the Union addresses, beginning in 2003, Bush urged the US Congress to pass what he called medical liability reform. He justified that reform, which urged the capping of pain-and-suffering awards at US $\$ 250000$, by touting the need to ensure access to health care and to control rising costs.

The reform campaign was conducted against a backdrop of rising insurance premiums for US doctors. Despite the fact that volatile premiums have largely been found to be products of the insurance underwriting cycle (a cycle of gains and losses within the insurance industry), Bush, some Republicans, medical societies, hospitals and insurers exploited the "crisis," pushing lawmakers to make it more difficult for injured patients to sue doctors.

In fact, there is no evidence that doctors were hit with increasing numbers of malpractice claims during 20012004. Over the past 15 years, states that require insurers to file reports on malpractice claims indicate that rates have remained flat, or have even declined, relative to economic growth and population increases.

The real problem, says Tom Baker, a law professor at the University of Pennsylvania, is "not too much litigation, but too much malpractice. ... The idea that Americans are suit-happy, litigation-crazy, and ready to rumble in the courts is one of the more amazing myths of our time."

In his 2005 book The Medical Malpractice Myth, Baker claims doctors, patients, legislators and voters have been misdirected and should be seeking

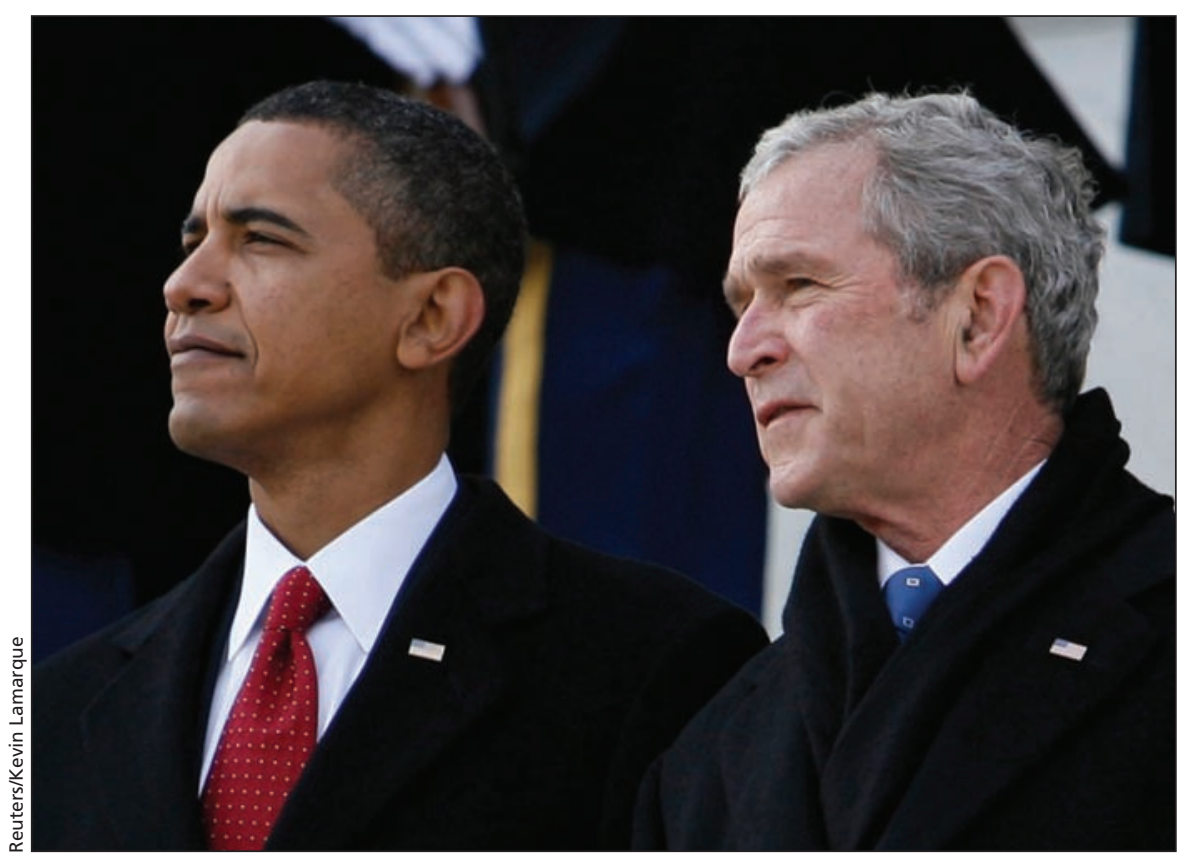

Former US president George W. Bush claimed there were too many frivolous medical malpractice lawsuits in the United States. His campaign for malpractice reform centered on capping pain-and-suffering awards. President Barack Obama, however, appears to favour reducing medical errors over tort reform.

ways to prevent malpractice. "It's not pretty to say, but doctors and nurses make preventable mistakes that kill more people in the United States every year than workplace and automobile accidents combined."

The best-available research supports Baker's position. Most Americans injured by medical malpractice do not sue. Most lawsuits are not frivolous, and courts efficiently weed out weak claims. Jury awards have not spiralled out of control, and lawsuits have not reduced access to doctors.

In a landmark study, the Institute of Medicine of the National Academy of Sciences estimated that medical errors kill up to 98000 US hospital patients each year (Kohn LT, Corrigan JM, Donaldson MS, editors. To Err is Human: Building a Safer Health System. Washington, DC; 2000). In 2004, Healthgrades, an independent health care ratings company, reported nearly double that figure. Its examination of
37 million patient records from all 50 states, representing $45 \%$ of all US hospital admissions, found 195000 hospital deaths from preventable medical errors annually between 2000 and 2002, (www.healthgrades.com).

"It's really an epidemic," says Joanne Doroshow, who heads the New York-based Center for Justice and Democracy, a nonprofit, nonpartisan consumer rights organization. "It's a terrible problem we have in this country, and I imagine around the world. Hospitals are dangerous places."

Evidence that medical malpractice in the US greatly exceeds malpractice lawsuits has been available since 1974, when California's medical and hospital associations sponsored a study intended to buttress their efforts to get lawmakers to pass tort reform. Instead, it found that doctors and hospitals negligently injured $0.8 \%$ of hospital patients (Mills $\mathrm{DH}$, editor. Report on the Medical Insurance Feasibility Study. Sacramento: 
California Medical Association and California Hospital Association; 1977). A later analysis of the data found that, at most, only 1 in 75 of those injured were compensated (Danzon, Patricia A. Medical Malpractice: Theory, evidence and public policy. Cambridge: Harvard University Press; 1985).

Recent research has confirmed that malpractice is rampant and few medical errors result in legal claims. In 1990, Harvard researchers examined more than 30000 randomly selected records from New York hospitals. They concluded that $1 \%$ of patients were negligently injured, while only $4 \%$ of those who were injured, sued (Patients, doctors and lawyers: Medical injury, malpractice litigation, and patient compensation in New York. Cambridge: Harvard University Press; 1990).

The notion that frivolous lawsuits abound is also unsubstantiated. A 2007 study by Public Citizen showed the court system was "on the whole, a rational one that provides money for valid claims and dismisses invalid ones," (www.citizen.org). Using data from the US government's National Practitioner Data Bank, the consumer nonprofit group concluded that complaints by "the business and medical lobbies are exaggerated and unsupported by the facts."

Harvard researchers reached a similar conclusion when they examined files from 1452 malpractice claims (NEJM 2006;354[19]:2024-33). A1most three-quarters had outcomes consistent with their merit. Only $10 \%$ of patients received payouts in the absence of error, while $16 \%$ received no payout despite the presence of error. "Portraits of a malpractice system that is stricken with frivolous litigation are overblown," the researchers concluded. The system performs "reasonably well" in dismissing such lawsuits and in compensating the injured.

In addition, there is evidence that jury awards are simply keeping up with the costs of medical care, rather than being out of line. In 2005, Dartmouth College economists studied payments made to patients between 1991 and 2003. Actual payments, not jury awards, grew an average of $4 \%$ annu- ally — slowing to $1.6 \%$ a year since 2000 - or $52 \%$ since 1991 , roughly equivalent to increases in health care costs (Health Aff January-June 2005; suppl Web exclusives:W5-240-W5249). A 2004 RAND study examining 40 years of jury verdicts concluded that average payouts grew by less than real income, with more costly medical care responsible for more than half the growth in jury awards.

In 2007, Americans for Insurance Reform used the insurance industry's own data to show that higher insurance premiums between 2001 and 2004 were not the result of sudden increases in claims and payouts. Instead, payouts per doctor were stable, or fell, with premium increases unconnected to actual payouts. Malpractice insurers "vastly" and "unnecessarily" increased reserves for future claims, the study found, (www.centerjd .org/air/StableLosses2007.pdf).

Even if caps and other limits on torts are imposed, they do not decrease malpractice premiums, according to the Center for Democracy and Justice. In 2002, it compared malpractice premiums to the amount of state-level tort "reform." Premiums did not decrease as tort law was restricted. Some states that resisted enacting changes to malpractice lawsuits had low premium increases; some states that made major changes had high increases. "Laws that restrict the rights of injured consumers to go to court do not produce lower insurance costs or rates," the report concluded. "And insurance companies that claim they do are severely misleading this country's lawmakers," (www.centerjd.org/archives /issues-facts/ANGOFFReport.pdf).

Overall, malpractice insurance and claims account for, at most, $2 \%$ of US health care spending, according to the US General Accounting Office, the investigative arm of Congress.

Allegations that the threat of lawsuits and high premiums were driving doctors out of business were also unfounded, according to an extensive investigation by the General Accounting Office into anecdotal stories from 5 "crisis" states, so-classified by the American Medical Association. The investigation concluded that access to health care was not widely affected, and that the number of physician departures were sometimes inaccurate.

The problem of volatile premiums won't be solved without reform of the insurance industry, says Doroshow. In most states, insurance companies can raise rates without government oversight. Requiring companies to justify rate hikes in regulatory hearings could control fluctuations, she says. And forcing malpractice insurance companies to open their books would increase competition in the industry.

The political debate has begun to refocus, a reflection that the real malpractice problem concerns the number of injured patients who don't receive compensation, says Baker. "The political rhetoric has shifted pretty dramatically in that direction."

As a senator, US President Barack Obama recognized the fallacy of the tort-reform remedy. In 2005, Obama and then-Senator Hillary Clinton cosponsored legislation aimed at reducing malpractice suits by reducing the number of patients medical malpractice killed or injured. During his campaign, Obama's health platform called for doctors and hospitals to be required to report preventable errors. He also promised support to providers to create guidelines and technology to prevent future errors.

In the years ahead, as Obama and the Democrats focus on health care reform, US anesthesiologists are likely to serve as the model for patient-safety improvements. Anesthesiologists once sued more than any other speciality and once paid some of the highest malpractice premiums in the country. In the 1980s, the American Society of Anesthesiologists scoured every claim filed against its members to identify unsafe practices and developed new guidelines to reduce errors. The anesthesiologists are now among the safest practitioners, and their insurance rates have fallen. Similarly, some US hospitals have recently examined malpractice claims made against them to find ways to make procedures safer, resulting in fewer lawsuits and lower litigation costs. - Janet Brooks, Salt Lake City, Utah

DOI:10.1503/cmaj.090129 